\title{
Computation of Compressive Strength of GGBS Mixed Concrete using Machine Learning
}

\author{
Swati, Jitendra Khatti, Kamaldeep Singh Grover
}

\begin{abstract}
Concrete is a composite material formed by cement, water, and aggregate. Concrete is an important material for any Civil Engineering project. Several concretes are produced as per the functional requirements using waste materials or byproducts. Many researchers reported that these waste materials or by-products enhance the concrete properties, but the laboratory procedures for determining the concrete properties are time-consuming. Therefore, numerous researchers used statistical and artificial intelligence methods for predicting concrete properties. In the present research work, the compressive strength of GGBS mixed concrete is computed using AI technologies, namely Regression Analysis (RA), Support Vector Machine (SVM), Decision Tree (DT), and Artificial Neural Networks (ANNs). The cement content (CC), C/F ratio, w/c ratio, GGBS (in $\mathrm{Kg} \& \%$ ), admixture, and age (days) are selected as input parameters to construct the RA, SVM, DT, ANNs models for computing the compressive strength of GGBS mixed concrete. The CS_MLR, Link_CS_SVM, 20LF_CS_DT, and GDM_CS_ANN models are identified as the best architectural AI models based on the performance of AI models. The performance of the best architectural AI models is compared to determine the optimum performance model. The correlation coefficient is computed for input and output variables. The compressive strength of GGBS mixed concrete is highly influenced by age (curing days). Comparing the performance of optimum performance AI models and models available in the literature study shows that the optimum performance AI model outperformed the published models.
\end{abstract}

Keywords: Compressive strength; GGBS, Support Vector Machine, Artificial Neural Networks

\section{I.INTRODUCTION}

\section{Concrete is the dominant construction material used in} any Civil Engineering project. It is a mixture of cement, aggregate, and water [19]. Plain cement concrete and reinforced cement concrete are types of concrete. The plain cement concrete performs better in compression, but it fails in tension. The reinforcements are provided to overcome this failure. Several supplementary cementitious materials (SCM) are used to improve the concrete properties.

Manuscript received on November 20, 2021.

Revised Manuscript received on November 26, 2021.

Manuscript published on November 30, 2021.

* Correspondence Author

Swati, M.Tech. Scholar, Department of Civil Engineering, Rajasthan Technical University, Kota (Rajasthan), India. E-mail. swatiachra@gmail.com

Jitendra Khatti, PhD Fellow, Department of Civil Engineering, Rajasthan Technical University, Kota (Rajasthan), India. E-mail. jitendrakhatti197@gmail.com

Kamaldeep Singh Grover, Professor, Department of Civil Engineering, Rajasthan Technical University, Kota (Rajasthan), India. E-mail. ksgrover@rtu.ac.in

(c) The Authors. Published by Blue Eyes Intelligence Engineering and Sciences Publication (BEIESP). This is an open access article under the CC BY-NC-ND license (http://creativecommons.org/licenses/by-nc-nd/4.0/)
These cementitious materials can be waste materials or byproducts. The limestone, natural pozzolana, silica fume, GGBS, and natural calcined pozzolana are the cementitious materials [4]. The published research works on the use of waste materials in the concrete show that the strength properties of concrete can be improved by adding a suitable quantity of waste material. Still, the determination of strength properties is time - consuming task. The strength properties of concrete are determined at twenty - eight days of curing. The compressive, flexural, and split tensile strength are the strength properties of concrete determined experimentally at 28,56, 90 days of curing. Numerous researchers applied statistical methods, namely simple, logistic, \& multiple regression analysis, and AI methods, namely SVM, GPR, DT, and ANN, etc., to compute the compressive strength of concrete.

By mapping the interrelationship with the water-cement ratio and the relative strength or gel/space ratio, the compressive strength of ordinary concrete can be predicted [15]. The artificial neural network removes the formation of complicated analytical equations. The precision of the neural network is the same while providing neurons in the range of 4 to 8 at the hidden layer [16]. In the early ages, it was assumed that the water-cement ratio played an important role in predicting the compressive strength of concrete. Still, one of the published articles reported that other concrete ingredients also influence the compressive strength of concrete. In the published work, the compressive strength of high-performance concrete was predicted using ANN because of the complexity of materials. The artificial neural network model outperformed the regression model in the published work [25]. The backpropagation neural networks outperformed the multiple regression analysis in predicting the strength and slump of the high-strength concrete and ready mixed concrete [9]. The grade of cement, w/c ratio, water dosages, and cement dosages, the maximum size of coarse aggregate, fine modulus of sand, sandaggregate ratio, aggregate-cement ratio, slump, admixture affect the prediction of compressive strength of concrete. The neural network makes better predictions of compressive strength as compared to regression analysis [10]. The artificial neural network has the potential to predict the compressive strength of concrete from 0 to 28 days of curing [17]. The genetic expression programming (GEP) outperforms the regression analysis and artificial neural network in predicting the compressive cement strength with the performance of $0.8803\left(\mathrm{R}^{2}=0.775\right)$ [2]. The GGBS enhances the strength properties of concrete. The GGBS was mixed at $20 \%, 40 \%, 60 \%$ and $80 \%$ for $0.3,0.4$ and $0.5 \mathrm{w} / \mathrm{c}$ ratio concrete.

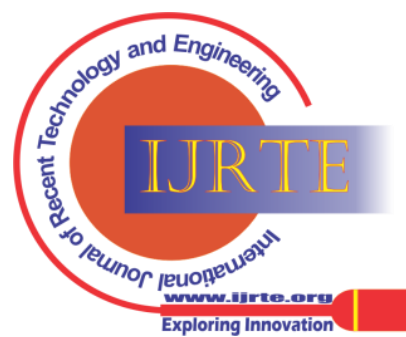




\section{Computation of Compressive Strength of GGBS Mixed Concrete using Machine Learning}

The authors computed the compressive strength of GGBS mixed concrete for 3, 7, 28, 90, 360 days of curing and reported that ANN can be an alternative technology for computing the compressive strength [3]. For any construction work, the compressive strength of concrete must be known. The authors predicted the compressive strength of concrete at 28 days using early age results. In this published study, the authors developed a rational polynomial equation and reported that the proposed equation can predict the compressive strength of concrete at 28 days of curing [12]. The fly ash (Class C) improves the compressive strength. The age, water binder ratio, fly ash content, and aggregate binder ratio plays an important role in predicting the compressive strength of concrete at 28 and 90 days of curing. The authors reported that the ANN can predict the compressive strength of concrete [20].

The dismantled concrete was used to improve the compressive strength of concrete. The compressive strength of concrete was predicted for 3, 7, 28, and 91 days of curing. The study was carried out using 1178 datasets of concrete. The ANN models were developed using 17 input parameters. After analyzing the results, it was concluded that the ANN has the potential to predict the compressive strength for 3, 7, 28, and 91 days of curing [8]. The twocoefficient-based rational polynomial equation can also predict the strength parameters of concrete [14]. The regression models were developed using w/c ratio, cementitious content, water content, workability, and curing days to predict the compressive strength of concrete. The authors reported that the proposed regression model predicted the compressive strength of concrete with an accuracy of 95\% [5]. The Levenberg-Marquardt algorithmbased ANN model outperforms the genetic programming model in predicting compressive strength [6]. The artificial neural network predicts silica fume and metakaolin mixed concrete's compressive strength more accurately than the MLR model [13]. The compressive strength of concrete was predicted using SVM, random forest, and ANN models. The random forest model outperformed the SVM and ANN model with a performance of 0.9497 [21]. The artificial neural network can predict the compressive strength of green concrete with a performance of $88.45 \%$ [22]. The ANN model can predict the compressive strength with high performance and accuracy [18] [24]. The artificial neural network has the potential to predict the compressive strength of cement mortar [1]. From the study of published articles, it has been observed that most of the authors used the artificial neural network AI approach to predict the compressive strength of concrete and results compared with regression, GEP, SVM model. The published research work was carried out using a different number of datasets. It has also been observed that the multiple regression, support vector machine, decision tree, and artificial neural network AI approaches have not been applied for predicting the compressive strength of GGBS mixed concrete. The present study has the following aims.

- Employ regression, support vector machine, decision tree, and artificial neural network models in MATLAB R2020a for predicting compressive strength of GGBS mixed concrete.
- Draw the correlation between input and output parameters of the model to determine the influence of input parameters on the prediction of compressive strength.

- Compare the performance of models to determine the optimum performance model.

- Draw the comparison of the performance of the optimum performance model with published models.

\section{II.METHODOLOGY}

The regression analysis (multiple regression analysis MLR), support vector machine (SVM), decision tree (DT), and artificial neural network (ANN) models have been used to predict the compressive strength of GGBS mixed concrete. The MLR, SVM, DT, ANN AI approaches have been discussed below with applied hyperparameters.

\subsection{Regression Analysis}

Regression analysis is the most powerful tool of statistics. The regression analysis is used for predicting and forecasting. The simple regression analysis is the fundamental regression analysis that consists of single dependent and independent variables. The multiple regression analysis consists of more than one dependent and independent variable. In the present study, multiple regression analysis has been performed to predict the compressive strength of concrete. An equation has been derived from the training of the multiple regression analysis (CS_MLR) model.

$\mathrm{CS} \_\mathrm{MLR}=86544-2.176 * \mathrm{CC}-49759 * \mathrm{C} / \mathrm{F}$ ratio $146.8 *$ w/c ratio $+13.346 *$ GGBS $(\mathrm{Kg})-50.69 * \mathrm{GGBS}(\%)-$ $6.129 * \mathrm{SP}+0.9228 *$ Age

Where CC is cement content, GGBS is ground granulated blast-furnace slag in \% and $\mathrm{Kg}, \mathrm{C} / \mathrm{F}$ ratio is coarse \& fine aggregate ratio, w/c ratio is the water-cement ratio, and SP is superplasticizer. Equation 1 has been used to predict the compressive strength of GGBS mixed concrete for different ages.

\subsection{Support Vector Machine}

The support vector machine (SVM) is based on supervised learning applied to solve the classification and prediction problems [7]. The SVM is inspired by statistical learning frameworks or developed by Vapnik (1995). In the present study, the support vector machine models have been developed using the Regression Learning Tool of MATLAB R2020a. The SVM is based on kernel functions, namely Gaussian, Linear, Quadratic, and Cubic. In the present work, the Gaussian, Linear, Quadratic, and Cubic kernel functions have been used to develop the SVM to predict the compressive strength of GGBS mixed concrete. The hyperparameters of SVM models are given in Table 1.

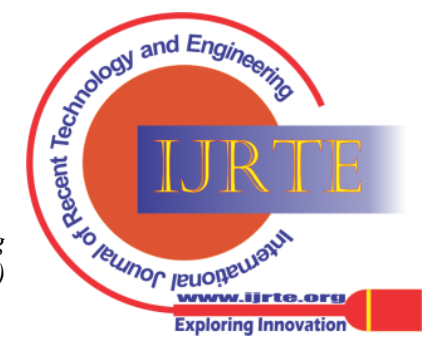


Table 1 - Hyperparameters of SVM models

\begin{tabular}{|l|c|c|}
\hline \multicolumn{1}{|c|}{ Hyperparameters } & Status & Values \\
\hline Kernel Functions & Auto & $\begin{array}{c}\text { Gaussian, Linear, Quadratic, } \\
\text { Cubic }\end{array}$ \\
\hline Box Constraint & Auto & Auto Calculated \\
\hline Kernel Scale & Auto & 1 \\
\hline Epsilon & Auto & Auto Calculated \\
\hline Standardize Data & Enable & Yes \\
\hline Optimizer & Enable & Bayesian Optimizer \\
\hline Acquisition Function & Enable & $\begin{array}{c}\text { Expected improvement per } \\
\text { second plus }\end{array}$ \\
\hline Iterations & Default & Default (30) \\
\hline Max. Training time (sec.) & Default & Default (300) \\
\hline Number of Grid Divisions & Default & Default (10) \\
\hline
\end{tabular}

The model architecture of Gaussian, Linear, Quadratic, and Cubic kernel functions-based SVM model is given in Table 2.

Table 2 - Architecture of SVM Models

\begin{tabular}{|l|c|c|}
\hline $\begin{array}{c}\text { Kernel } \\
\text { Function }\end{array}$ & $\begin{array}{c}\text { Kernel } \\
\text { Notation }\end{array}$ & Model Architecture \\
\hline Gaussian & GaussK & GaussK_CS_SVM \\
\hline Linear & LinK & LinK_CS_SVM \\
\hline Quadratic & QuadK & QuadK_CS_SVM \\
\hline Cubic & CubicK & CubicK_CS_SVM \\
\hline
\end{tabular}

The best architectural SVM model for predicting the compressive strength of GGBS mixed concrete is determined based on the performance comparison of SVM models.

\subsection{Decision Tree}

The decision tree is another supervised machine learning technique used to solve classification and regression or forecasting problems. A decision tree consists of nodes (node, root node, inner node, leaf) and branches. The architecture of a simple decision tree with nodes and branches is shown in Figure 1.

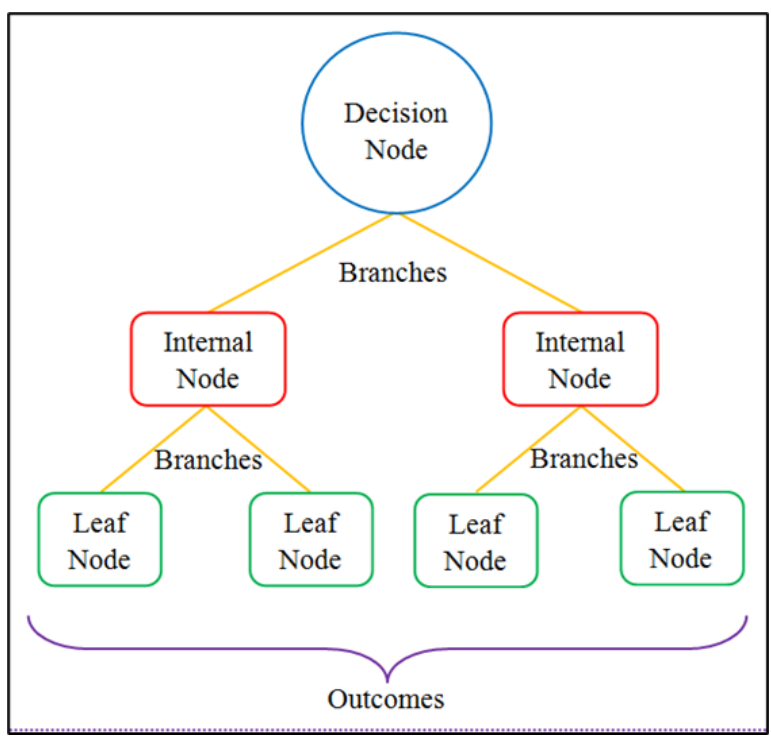

In this study, the twenty-leaf size decision tree has been employed in MATLAB R2020a to predict the compressive strength of GGBS mixed concrete. The model architecture of twenty leaf size-based DT model is 20LF_CS_DT. The hyperparameters of DT models are given in Table 3.
Figure 1. Architecture of simple decision tree

Table 3 - Hyperparameters of DT model

\begin{tabular}{|l|c|c|}
\hline \multicolumn{1}{|c|}{ Hyperparameters } & Status & Values \\
\hline Minimum Leaf Size & Manual & Twenty \\
\hline $\begin{array}{l}\text { Surrogate Decision } \\
\text { Splits }\end{array}$ & Default & Off \\
\hline $\begin{array}{l}\text { Max. Surrogates per } \\
\text { Nodes }\end{array}$ & Default & 10 \\
\hline Optimizer & Enable & Bayesian Optimizer \\
\hline Acquisition Function & Enable & $\begin{array}{c}\text { Expected improvement } \\
\text { per second plus }\end{array}$ \\
\hline Iterations & Default & Default (30) \\
\hline $\begin{array}{l}\text { Max. Training time } \\
\text { (sec.) }\end{array}$ & Default & Default (300) \\
\hline $\begin{array}{l}\text { Number of Grid } \\
\text { Divisions }\end{array}$ & Default & Default (10) \\
\hline
\end{tabular}

\subsection{Artificial Neural Networks}

The artificial neural network (ANN) is a network of layers, and these layers are interconnected with neurons. The ANN is based on supervised, unsupervised, and reinforcement learning. The artificial neural network is also used for solving regression and classification problems. The multilayer perceptron class-based ANN model is the most popular neural network. Every neural network model has feedforward and backpropagation processes to solve the issues. In the present study, the multilayer perceptron classbased ANN models have been developed with different backpropagation algorithms. The hyperparameters of ANN models are given in Table 4.

Table 4 - Hyperparameters of ANN model

\begin{tabular}{|l|l|}
\hline Hyperparameters & Value \\
\hline Hidden layer(s) & One \\
\hline Neurons & Ten \\
\hline Backpropagation algorithm(s) & $\begin{array}{l}\text { LM, BFG, SCG, GDM, GD, } \\
\text { GDM }\end{array}$ \\
\hline Activation function(s) & Sigmoid, Linear function \\
\hline Train: Validation ratio & $80: 20$ \\
\hline Epochs & 1000 \\
\hline Network type & Feedforward backpropagation \\
\hline Network class & Multilayer perceptron class \\
\hline Mu & 0.001 \\
\hline Max fail & 6 \\
\hline Min gradient & $10 \mathrm{e}-7$ \\
\hline
\end{tabular}

\section{III.DATA ANALYSIS}

The present study has been carried out using published datasets of Venu (2014). A total of 56 datasets have been used to develop regression, SVM, DT, and ANN models. The dataset consists of GGBS (in kg \& \%), cement content, fine aggregate content, coarse aggregate content, superplasticizer (in \%), age, and compressive strength. The $\mathrm{C} / \mathrm{F}$ ratio has been calculated from the coarse and fine aggregate. The cement content (CC), C/F ratio, GGBS (in $\mathrm{kg} \& \%$ ), superplasticizer (in \%) have been used as input parameters to develop the prediction models.

Published By:

Blue Eyes Intelligence Engineering and Sciences Publication (BEIESP)

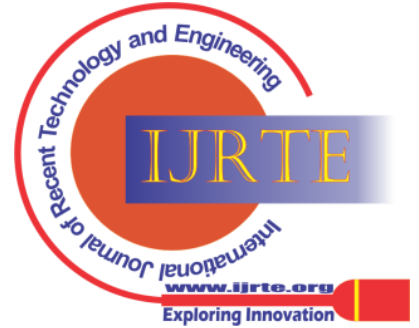




\section{Computation of Compressive Strength of GGBS Mixed Concrete using Machine Learning}

\subsection{Descriptive Statistics}

Descriptive statistics is a summary of the datasets used for studying the characteristics of datasets.

The statistics parameters are the minima, maxima, mean, mode, median, standard deviation (StDev), and confidence level (CL) at 95\%. The descriptive statistics of datasets are

Table 5 - Descriptive statistics of datasets of GGBS concrete

\begin{tabular}{|c|c|c|c|c|c|c|c|c|}
\hline $\begin{array}{c}\text { Particul } \\
\text { ars }\end{array}$ & $\begin{array}{c}\text { Ceme } \\
\text { nt } \\
(\mathbf{K g})\end{array}$ & $\begin{array}{c}\mathrm{C} / \mathrm{F} \\
\text { rati } \\
\mathbf{0}\end{array}$ & $\begin{array}{c}\mathrm{W} \\
\mathrm{C} \\
\text { rati } \\
\mathbf{0}\end{array}$ & $\begin{array}{c}\text { GG } \\
\text { BS } \\
(\mathrm{Kg})\end{array}$ & $\begin{array}{c}\text { GG } \\
\text { BS } \\
(\%)\end{array}$ & $\begin{array}{c}\text { SP } \\
\text { (\% } \\
\text { ) }\end{array}$ & $\begin{array}{c}\text { Age } \\
\text { (Day } \\
\text { s) }\end{array}$ & $\begin{array}{c}\text { CS } \\
\text { (Mp } \\
\text { a) }\end{array}$ \\
\hline Min & $\begin{array}{c}130.8 \\
0\end{array}$ & $\begin{array}{c}1.7 \\
2 \\
\end{array}$ & $\begin{array}{c}0.4 \\
5 \\
\end{array}$ & 0.00 & 0.00 & $\begin{array}{c}0.0 \\
0 \\
\end{array}$ & 3.00 & $\begin{array}{c}12.2 \\
8 \\
\end{array}$ \\
\hline Max & $\begin{array}{c}327.0 \\
0\end{array}$ & $\begin{array}{c}1.7 \\
2\end{array}$ & $\begin{array}{c}0.5 \\
0\end{array}$ & $\begin{array}{c}196 . \\
20\end{array}$ & $\begin{array}{c}60.0 \\
0\end{array}$ & $\begin{array}{c}1.0 \\
0\end{array}$ & $\begin{array}{c}28.0 \\
0\end{array}$ & $\begin{array}{c}41.2 \\
1\end{array}$ \\
\hline Mean & $\begin{array}{c}239.9 \\
8 \\
\end{array}$ & $\begin{array}{c}1.7 \\
2 \\
\end{array}$ & $\begin{array}{c}0.4 \\
7 \\
\end{array}$ & $\begin{array}{c}87.0 \\
1 \\
\end{array}$ & $\begin{array}{c}26.6 \\
1\end{array}$ & $\begin{array}{c}0.9 \\
3\end{array}$ & $\begin{array}{c}14.3 \\
9\end{array}$ & $\begin{array}{c}22.7 \\
0\end{array}$ \\
\hline Mode & $\begin{array}{c}327.0 \\
0\end{array}$ & $\begin{array}{c}1.7 \\
2\end{array}$ & $\begin{array}{c}0.4 \\
5\end{array}$ & 0.00 & 0.00 & $\begin{array}{c}1.0 \\
0\end{array}$ & 7.00 & $\begin{array}{c}14.3 \\
0\end{array}$ \\
\hline Median & $\begin{array}{c}237.1 \\
0\end{array}$ & $\begin{array}{c}1.7 \\
2\end{array}$ & $\begin{array}{c}0.4 \\
5\end{array}$ & $\begin{array}{c}89.9 \\
3\end{array}$ & $\begin{array}{c}27.5 \\
0\end{array}$ & $\begin{array}{c}1.0 \\
0\end{array}$ & 7.00 & $\begin{array}{c}20.0 \\
1\end{array}$ \\
\hline StDev & 58.07 & $\begin{array}{c}0.0 \\
0\end{array}$ & $\begin{array}{c}0.0 \\
2\end{array}$ & $\begin{array}{c}58.1 \\
0\end{array}$ & $\begin{array}{c}17.7 \\
6\end{array}$ & $\begin{array}{c}0.2 \\
6\end{array}$ & $\begin{array}{c}10.3 \\
2\end{array}$ & 9.16 \\
\hline $\begin{array}{l}\text { CL } \\
(95 \%)\end{array}$ & 15.55 & $\begin{array}{c}0.0 \\
0 \\
\end{array}$ & $\begin{array}{c}0.0 \\
1 \\
\end{array}$ & $\begin{array}{c}15.5 \\
6\end{array}$ & 4.76 & $\begin{array}{c}0.0 \\
7\end{array}$ & 2.76 & 2.45 \\
\hline
\end{tabular}

\subsection{Pearson's Correlation Coefficient}

Pearson's product-moment is the method of determining the relationship between input and output variables. The Pearson's correlation coefficient has been calculated for compressive strength of GGBS mixed concrete, as given in Table 6 in terms of Pearson's matrix.

Table 6 - Pearson's matrix of datasets of GGBS mixed concrete

\begin{tabular}{|c|c|c|c|c|c|c|c|c|}
\hline $\begin{array}{c}\text { Correlat } \\
\text { ion (R) }\end{array}$ & $\begin{array}{c}\text { Ceme } \\
\text { nt } \\
(\mathrm{Kg})\end{array}$ & $\begin{array}{c}\mathrm{C} / \\
\mathbf{F} \\
\text { rati } \\
\mathbf{0}\end{array}$ & $\begin{array}{c}\text { W } \\
\text { C } \\
\text { rati } \\
0\end{array}$ & $\begin{array}{c}\text { GG } \\
\text { BS } \\
(\mathrm{Kg})\end{array}$ & $\begin{array}{c}\text { GG } \\
\text { BS } \\
(\%)\end{array}$ & $\begin{array}{c}\text { SP } \\
(\% \\
)\end{array}$ & $\begin{array}{c}\text { Age } \\
\text { (Day } \\
\text { s) }\end{array}$ & $\begin{array}{c}\text { CS } \\
\text { (Mp } \\
\text { a) }\end{array}$ \\
\hline $\begin{array}{l}\text { Cement } \\
(\mathrm{Kg})\end{array}$ & 1.00 & - & - & - & - & - & - & - \\
\hline $\mathrm{C} / \mathrm{F}$ ratio & 0.45 & $\begin{array}{c}1.0 \\
0\end{array}$ & - & - & - & - & - & - \\
\hline WC ratio & 0.58 & $\begin{array}{c}0.3 \\
2\end{array}$ & $\begin{array}{c}1.0 \\
0\end{array}$ & - & - & - & - & - \\
\hline $\begin{array}{l}\text { GGBS(K } \\
\text { g) }\end{array}$ & 1.00 & $\begin{array}{c}0.4 \\
5\end{array}$ & $\begin{array}{c}0.5 \\
8\end{array}$ & 1.00 & - & - & - & - \\
\hline $\begin{array}{l}\text { GGBS } \\
(\%)\end{array}$ & 1.00 & $\begin{array}{c}0.4 \\
5\end{array}$ & $\begin{array}{c}0.5 \\
8\end{array}$ & 1.00 & 1.00 & - & - & - \\
\hline SP (\%) & 0.65 & $\begin{array}{c}0.7 \\
0\end{array}$ & $\begin{array}{c}0.2 \\
7\end{array}$ & 0.65 & 0.65 & $\begin{array}{c}1.0 \\
0\end{array}$ & - & - \\
\hline $\begin{array}{l}\text { Age } \\
\text { (Days) }\end{array}$ & 0.22 & $\begin{array}{c}0.3 \\
9\end{array}$ & $\begin{array}{c}0.5 \\
2\end{array}$ & 0.22 & 0.22 & $\begin{array}{c}0.2 \\
9\end{array}$ & 1.00 & - \\
\hline $\begin{array}{l}\text { CS } \\
\text { (Mpa) }\end{array}$ & 0.37 & $\begin{array}{c}0.3 \\
3\end{array}$ & $\begin{array}{c}0.4 \\
0\end{array}$ & 0.37 & 0.37 & $\begin{array}{c}0.2 \\
1\end{array}$ & 0.93 & 1.00 \\
\hline
\end{tabular}

The graphical presentation of the relationship between input parameters and compressive strength of GGBS mixed concrete is shown in Figure. 2 given in Table 5.

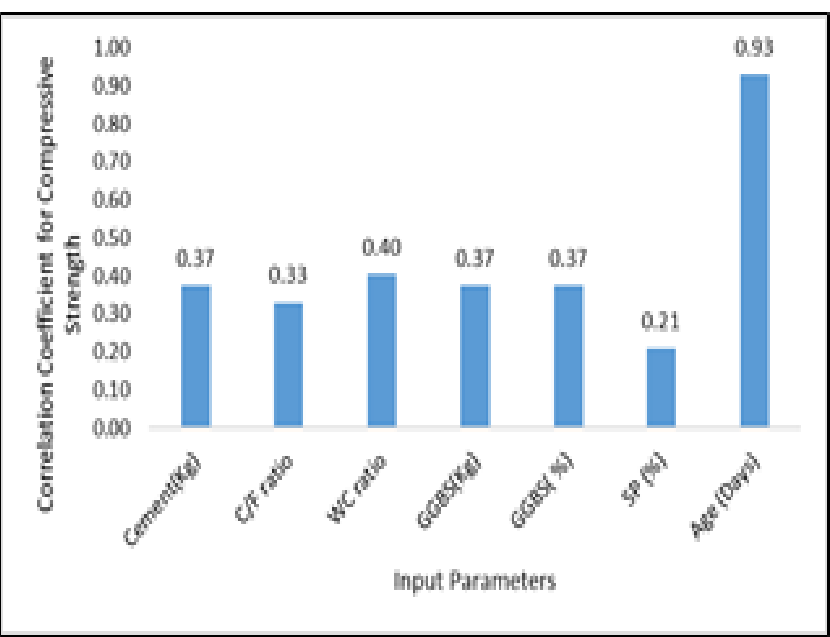

Figure 2. Relationship between input parameters and compressive strength

Figure 2 shows that the cement, C/F ratio, w/c ratio, GGBS, SP have a weak relationship with the compressive strength of concrete, but age (curing days) has a very strong correlation [11]. The correlation coefficient shows that the compressive strength of GGBS mixed concrete is influenced by curing days.

\subsection{Training, Validation, and Testing Datasets}

The regression analysis, support vector machine, decision tree, and artificial neural network models have been developed to predict the compressive strength. The datasets are divided into the following for developing AI models, as shown in Table 7.

Table 7 - Divisions of datasets used in this study

\begin{tabular}{|c|c|c|c|}
\hline Approach & Training Data & $\begin{array}{c}\text { Validation } \\
\text { Data }\end{array}$ & Testing Data \\
\hline MLR & 43 & - & 13 \\
\hline SVM & 43 & - & 13 \\
\hline DT & 43 & - & 13 \\
\hline ANN & 34 & 09 & 13 \\
\hline
\end{tabular}

\section{IV.RESULTS AND DISCUSSIONS}

The results and performance of Multilinear Regression Analysis, Support Vector Machine, Decision Tree, and Artificial Neural Network have been discussed. The models have been developed to predict the compressive strength of GGBS mixed concrete. The performance of constructed AI models has been calculated in terms of MAE, RMSE, and R. The mathematical expression of MAE, RMSE, and R is -

$$
\begin{gathered}
M A E=\frac{1}{N}\left(\sum_{i=1}^{N} \operatorname{abs}\left(T_{i}-P\right)_{i}\right) \\
R M S E=\sqrt{\frac{1}{N} \sum_{i=1}^{N}\left(T_{i}-P_{i}\right)^{2}} \\
R=\frac{\sum_{i=1}^{N}\left(T_{i}-\bar{T}\right)\left(P_{i}-\bar{P}\right)}{\sqrt{\sum_{i=1}^{N}\left(T_{i}-\bar{T}\right)^{2} \sum_{i=1}^{N}\left(P_{i}-\bar{P}\right)^{2}}}
\end{gathered}
$$

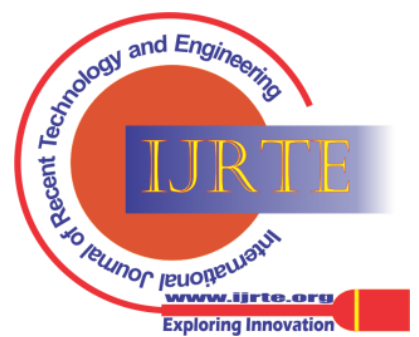


The best architecture model has been identified based on the performance of AI models.

The following four AI models have also been compared to identify the optimum performance AI model for predicting the compressive strength of GGBS mixed concrete specimen.

\subsection{Multilinear Regression Analysis}

The multilinear regression model (CS_MLR) is used for predicting the compressive strength of GGBS mixed concrete. The training and testing performance of the CS_MLR model is shown in Table 8.

\section{Table 8 - Performance of CS_MLR Model for Cs of} GGBS Mixed Concrete

\begin{tabular}{|c|c|c|c|c|c|}
\hline \multicolumn{2}{|c|}{ Training Performance } & \multicolumn{3}{c|}{ Testing Performance } \\
\hline RMSE & R & MAE & RMSE & R & MAE \\
\hline 2.2053 & 0.9744 & 1.7274 & 3.3224 & 0.9379 & 2.6946 \\
\hline
\end{tabular}

From Table 8, it has been observed that the CS_MLR model has achieved a performance of 0.9379 in predicting the compressive strength of GGBS mixed concrete. The predicted and laboratory compressive strength of 13 GGBS mixed concrete specimens has been compared, as shown in Figure 3.

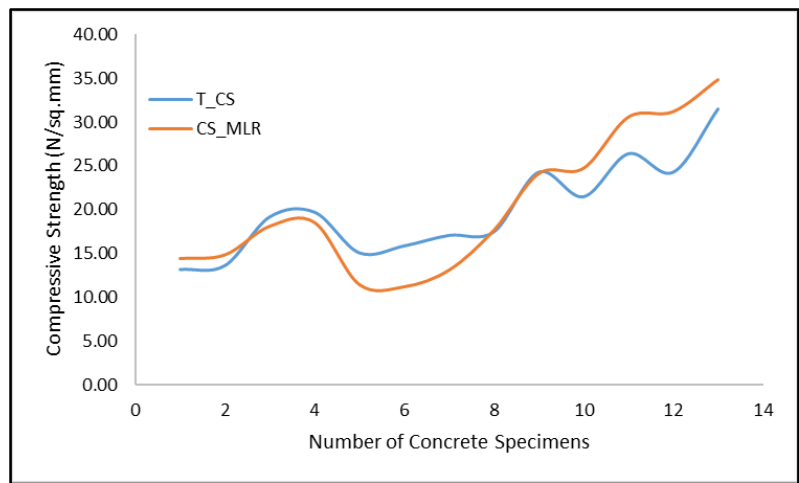

Figure 3. Comparison of test and predicted CS using CS_MLR model

Figure 3 shows that the CS_MLR has predicted compressive strength of GGBS mixed concrete approximately equal to laboratory results. Hence, the CS_MLR model may be used for predicting the preliminary compressive strength of GGBS mixed concrete. The actual vs predicted plot is mapped to calculate the coefficient of determination. The coefficient of determination $\left(\mathrm{R}^{2}\right)$ has been calculated for the predicted compressive strength of GGBS mixed concrete using the CS_MLR model, as shown in Figure 4.

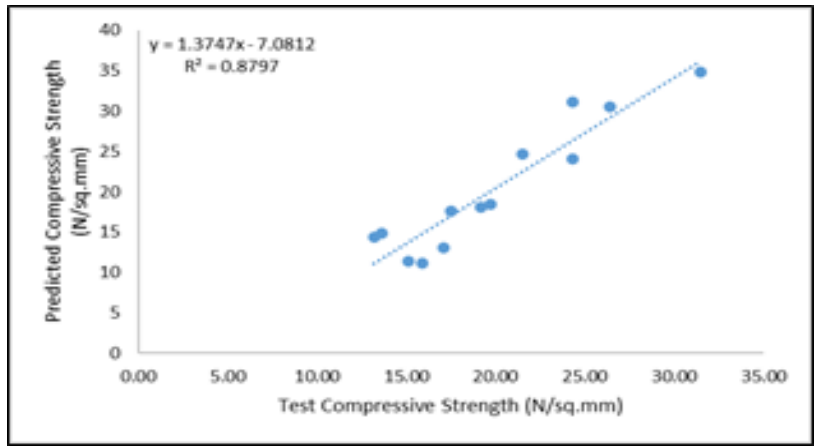

Figure 4. R2 for the predicted CS using CS_MLR model
From Figure 4, it has been observed that the CS_MLR model has predicted the compressive strength of GGBS mixed concrete with $\mathrm{R}^{2}=0.8797$. The residuals in predicting the compressive strength of GGBS mixed concrete have been calculated, as shown in Figure 5.

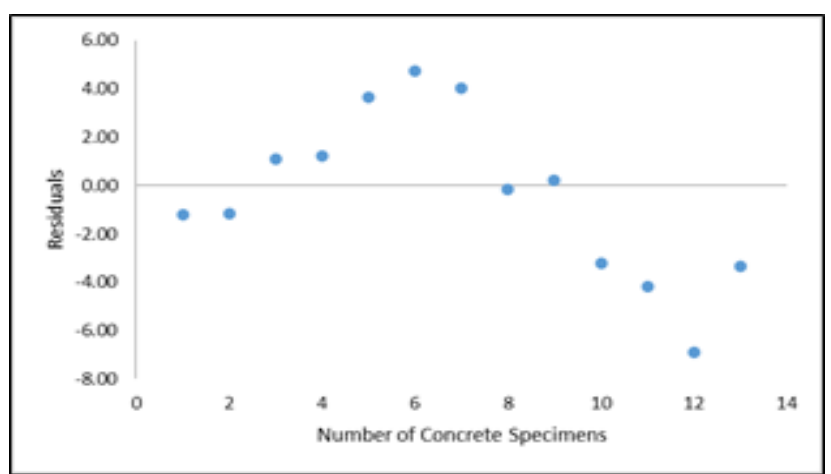

Figure 5. Residuals plot for predicted CS using CS_MLR model

From Figure 5, it has been observed that the CS_MLR model has predicted the compressive strength of GGBS mixed concrete with the variation of \pm 8.0 . The confidence and prediction interval of computed compressive strength of GGBS mixed concrete using the CS_MLR model has been mapped, as shown in Figure 6.

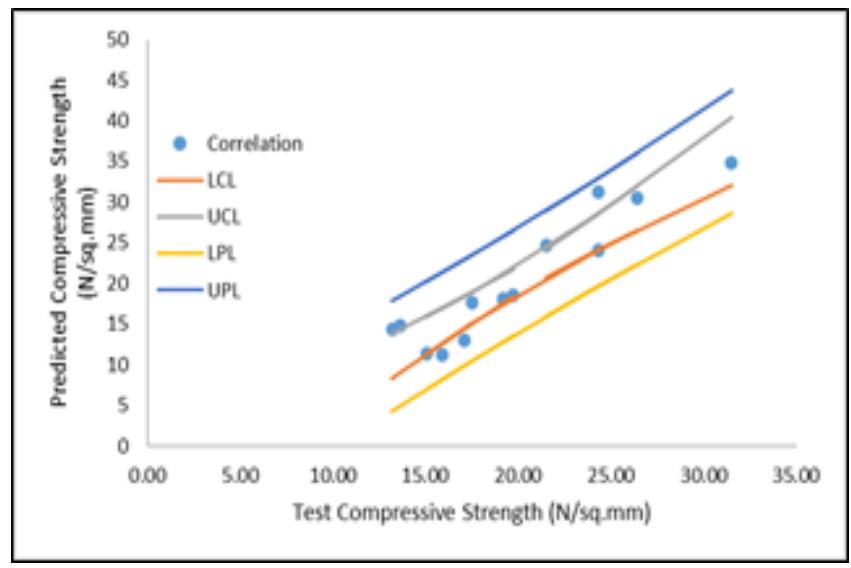

Figure 6. Confidence and prediction interval of computed CS using CS_MLR model

From Figure 6, it has been observed that the CS_MLR model has predicted compressive strength of GGBS mixed concrete with $\pm 5.65 \%$ confidence and $\pm 13.69 \%$ prediction intervals.

\subsection{Support Vector Machine}

Four support vector machine models have been constructed using Linear, Gaussian, Quadratic, and Cubic kernel functions to compute the compressive strength of GGBS mixed concrete. The Linear, Gaussian, Quadratic, and Cubic kernel function-based SVM models are designated as LinK_CS_SVM, GaussK_CS_SVM, QuadK_CS_SVM, CubicK_CS_SVM, respectively. The training and testing performance of the SVM models of compressive strength of GGBS mixed concrete is shown in Table 9.

Published By:

Blue Eyes Intelligence Engineering and Sciences Publication (BEIESP) 


\section{Computation of Compressive Strength of GGBS Mixed Concrete using Machine Learning}

Table 9 - Performance of SVM Models for CS of GGSB Mixed Concrete

\begin{tabular}{|l|c|c|c|c|c|c|}
\hline \multirow{2}{*}{ SVM Model } & \multicolumn{3}{|c|}{ Training Performance } & \multicolumn{2}{c|}{ Testing Performance } \\
\cline { 2 - 7 } & RMS & R & MAE & RMS & R & MAE \\
& E & & & & & \\
\hline LinK_CS_SVM & 3.027 & 0.953 & 2.231 & 3.450 & 0.927 & 2.508 \\
& 1 & 9 & 4 & 5 & 3 & 7 \\
\hline GaussK_CS_SV & 2.298 & 0.974 & 1.336 & 3.517 & 0.833 & 2.727 \\
M & 4 & 7 & 5 & 1 & 3 & 6 \\
\hline QuadK_CS_SV & 1.494 & 0.989 & 1.018 & 3.587 & 0.748 & 1.938 \\
M & 1 & 9 & 6 & 7 & 4 & 0 \\
\hline CubicK_CS_SV & 2.746 & 0.959 & 1.805 & 3.849 & 0.926 & 3.439 \\
M & 9 & 2 & 7 & 4 & 0 & 2 \\
\hline
\end{tabular}

From Table 9, it has been observed that the LinK_CS_SVM model has achieved a maximum performance of 0.9273 in predicting the compressive strength of GGBS mixed concrete. The performance curve of the Link_CS_SVM model is shown in Figure 7.

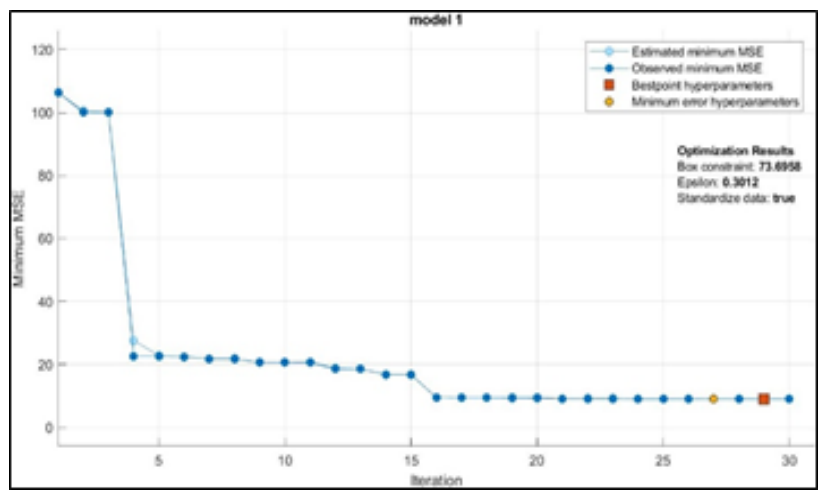

Figure 7. Performance of Link_CS_SVM model for predicting CS

From Figure 7, it has been observed that the best prediction of compressive strength of GGBS mixed concrete has been achieved at the $29^{\text {th }}$ iteration with RMSE $=3.4505$, which is comparatively less than other SVM models of compressive strength of GGBS mixed concrete. The LinK_CS_SVM model has been used to predict the compressive strength, and predicted compressive strength has been compared with laboratory compressive strength, as shown in Figure 8.

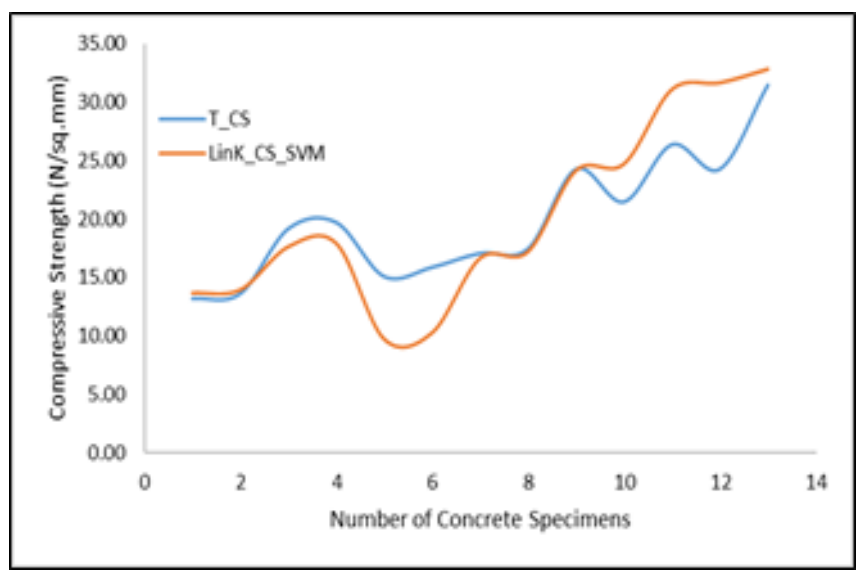

Figure 8. Comparison of test and predicted CS using LinK_CS_SVM model

Figure 8 shows that the LinK_CS_SVM model has predicted the compressive strength of GGBS mixed concrete, which is nearly equal to laboratory results. Hence, the LinK_CS_SVM model may be used for predicting the

preliminary compressive strength of GGBS mixed concrete. The actual vs predicted plot is mapped to calculate the coefficient of determination. The $\mathrm{R}^{2}$ has been calculated for the predicted compressive strength of GGBS mixed concrete using LinK_CS_SVM, as shown in Figure 9.

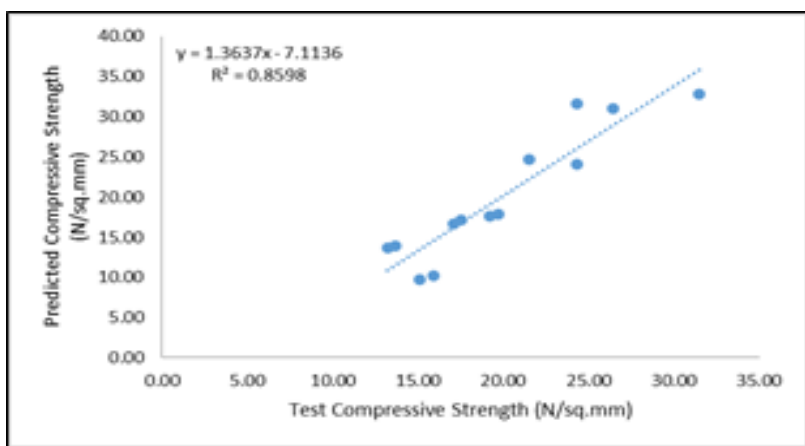

Figure 9. R2 for the predicted CS using LinK_CS_SVM model

From Figure 9, it has been observed that the LinK_CS_SVM models have predicted the compressive strength of GGBS mixed concrete with $\mathrm{R}^{2}=0.8598$. The residuals in predicting the CS of GGBS mixed concrete have been calculated, as shown in Figure 10.

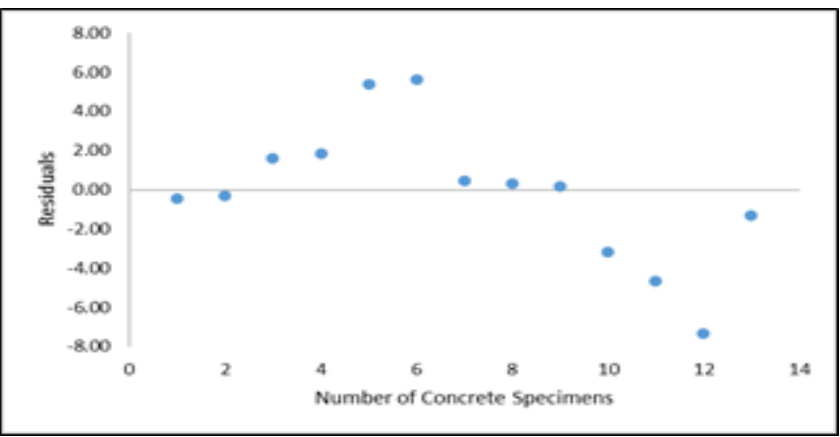

Figure 10. Residuals plot for predicted CS using LinK_CS_SVM model

From Figure 10, it has been observed that the LinK_CS_SVM model has predicted the compressive strength of GGBS mixed concrete with the variation of \pm 10.0 in compressive strength. The confidence and prediction interval of computed compressive strength of GGBS mixed concrete using the LinK_CS_SVM model has been mapped, as shown in Figure 11.

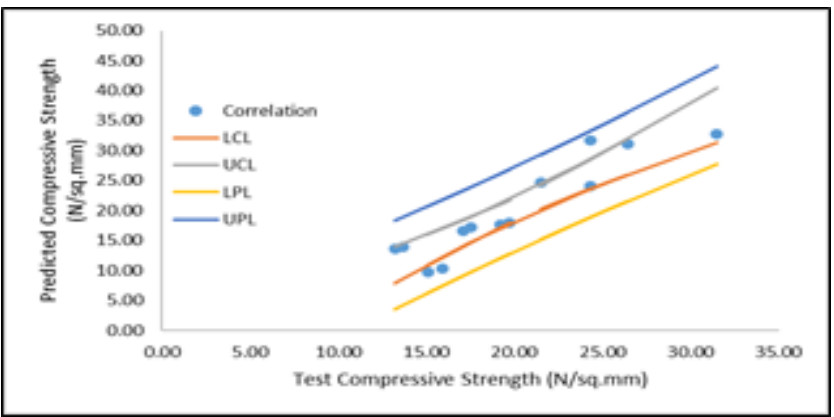

Figure 11. Confidence and prediction interval of computed CS using Link_CS_SVM model

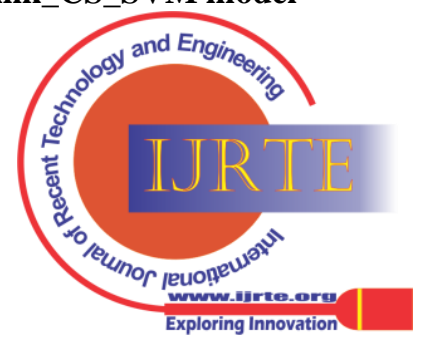


From Figure 11, it has been observed that the LinK_CS_SVM model has predicted compressive strength of GGBS mixed concrete with $\pm 6.12 \%$ confidence and $\pm 14.83 \%$ prediction intervals.

\subsubsection{Decision Tree}

The decision tree (DT) model has been constructed using a twenty-leaf size to compute the compressive strength of GGBS mixed concrete. The decision tree model is designated as 20LF_CS_DT, where LF is leaf size selected automatically for the best prediction. The training and testing performance of the DT model of compressive strength of GGBS mixed concrete is shown in Table 10

Table 10 - Performance of DT Model for CS of GGBS Mixed Concrete

\begin{tabular}{|l|c|c|c|c|c|c|}
\hline \multirow{2}{*}{$\begin{array}{c}\text { DT Model } \\
\text { Architecture }\end{array}$} & \multicolumn{2}{|c|}{ Training Performance } & \multicolumn{3}{c|}{ Testing Performance } \\
\cline { 2 - 7 } & $\begin{array}{c}\text { RMS } \\
\text { E }\end{array}$ & $\mathbf{R}$ & MAE & $\begin{array}{c}\text { RMS } \\
\text { E }\end{array}$ & R & MAE \\
\hline 20LF_CS_D & & 0.938 & 2.110 & & 0.956 & 1.228 \\
T & 3.4227 & 1 & 3 & 1.8514 & 6 & 8 \\
\hline
\end{tabular}

From Table 10, it has been observed that the 20LF_CS_DT model has achieved a performance of 0.9566 in predicting the compressive strength of GGBS mixed concrete. The performance curve of the 20LF_CS_DT model is shown in Figure 12.

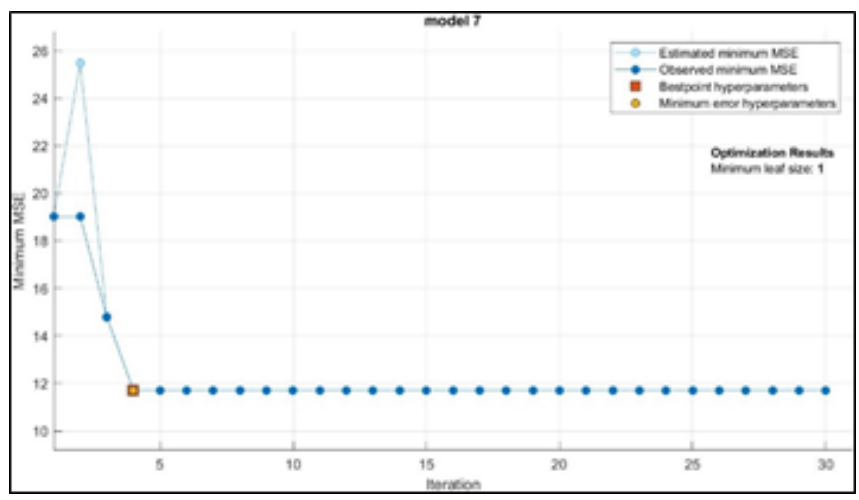

Figure 12. Performance of 20LF_CS_DT model for predicting CS of concrete strength of GGBS mixed concrete has been achieved at the $4^{\text {th }}$ iteration with RMSE $=0.9566$. The 20LF_CS_DT model has been used to predict the compressive strength and predicted compressive strength has been compared with laboratory compressive strength, as shown in Figure 13.

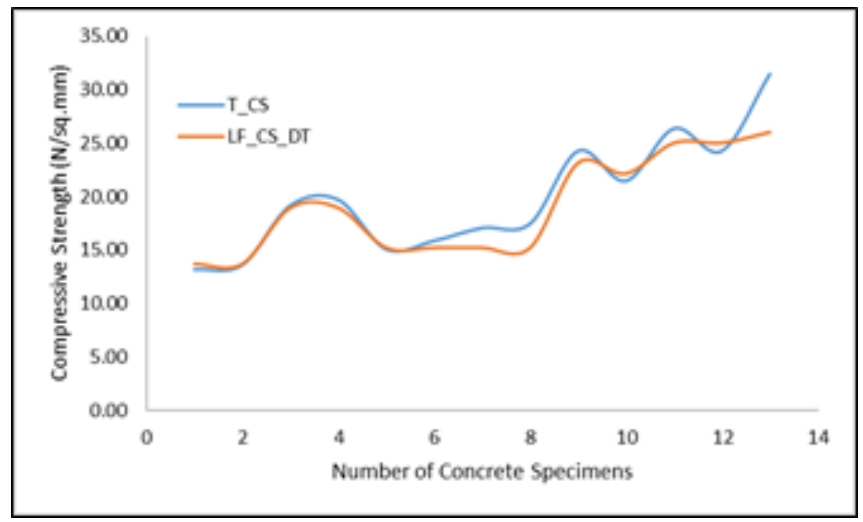

Fig- 13 Comparison of test and predicted CS using 20LF_CS_DT model
Figure 12 shows that the best prediction of compressive

Figure 13 shows that the 20LF_CS_DT model has predicted the compressive strength of GGBS mixed concrete, which is equal to laboratory results. Hence, the 20LF_CS_DT model may be used for predicting the preliminary compressive strength of GGBS mixed concrete. The actual vs predicted plot is mapped to calculate the coefficient of determination. The coefficient of determination $\left(\mathrm{R}^{2}\right)$ has been calculated for the predicted compressive strength of GGBS mixed concrete using 20LF_CS_DT, as shown in Figure 14.

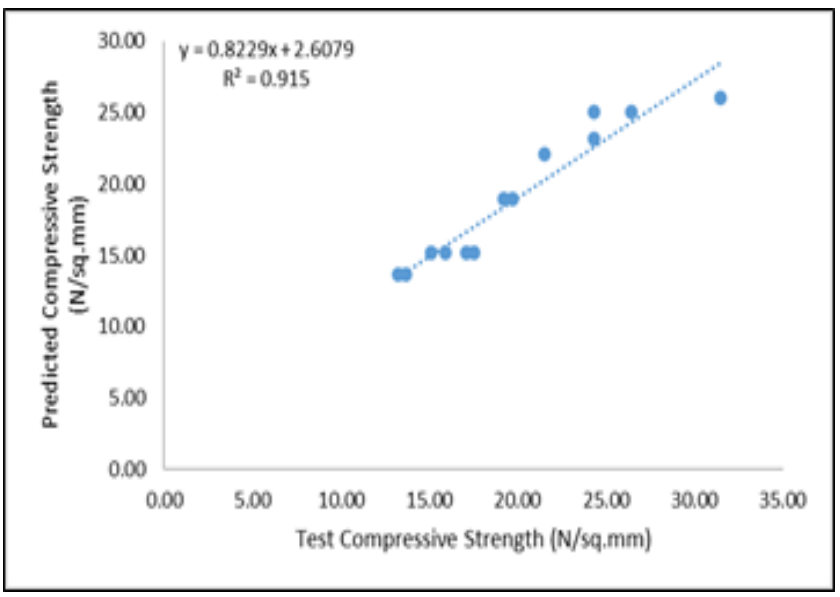

Figure 14 R2 for the predicted CS using 20LF_CS_DT model

Figure 14 shows that the 20LF_CS_DT models have predicted compressive strength of GGBS mixed concrete with $\mathrm{R}^{2}=0.9150$. The residuals in predicting the compressive strength of GGBS mixed concrete have been calculated, as shown in Figure 15.

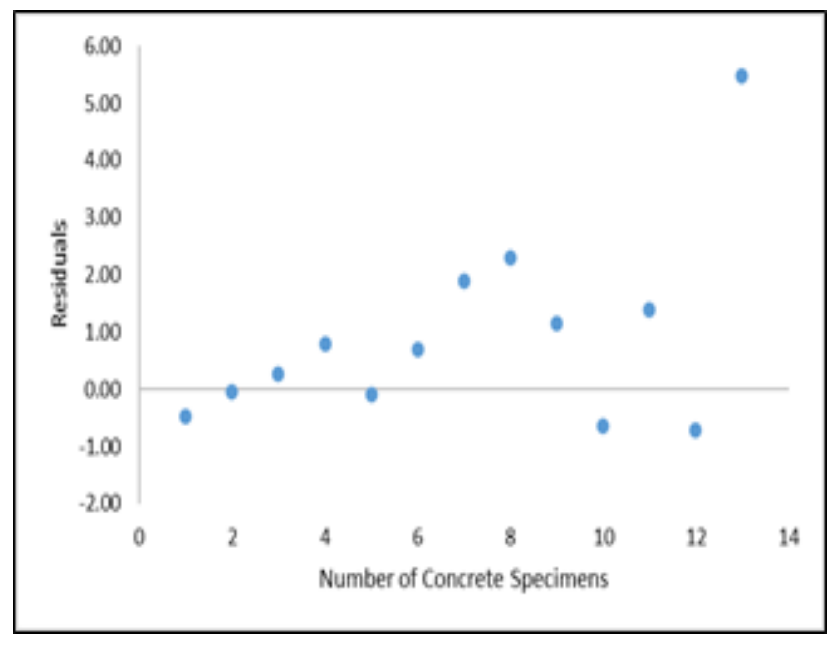

Figure 15. Residuals plot for predicted CS using 20LF_CS_DT model

From Figure 15, it has been observed that the 20LF_CS_DT model has predicted the compressive strength of GGBS mixed concrete with the variation of \pm 6.0 in compressive strength. The confidence and prediction interval of computed compressive strength of GGBS mixed concrete using the 20LF_CS_DT model has been mapped, as shown in Figure 16.

Published By:

Blue Eyes Intelligence Engineering and Sciences Publication (BEIESP)

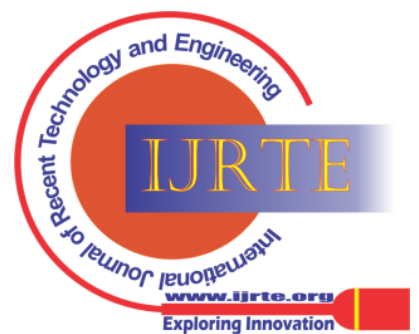




\section{Computation of Compressive Strength of GGBS Mixed Concrete using Machine Learning}

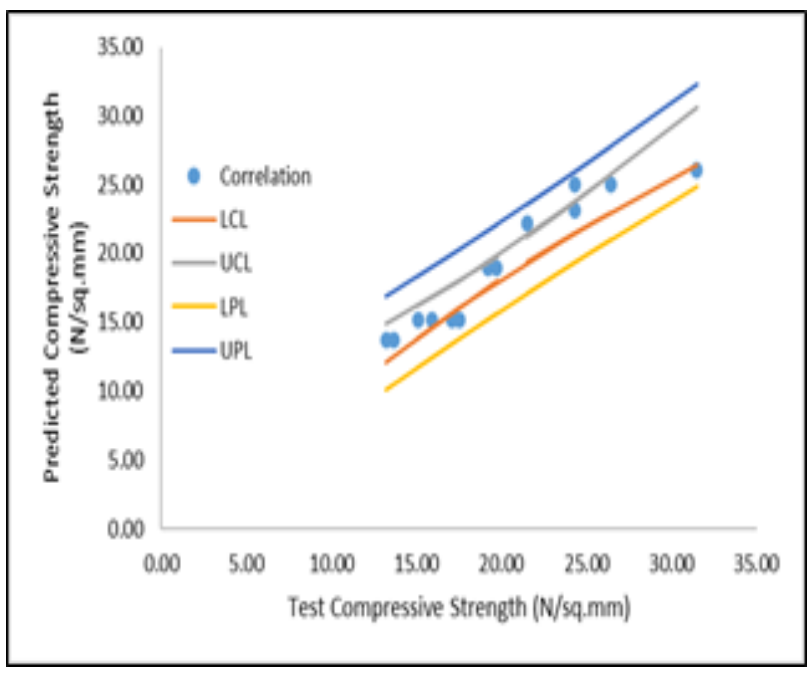

Figure 16. Confidence and prediction interval of computed CS using 20LF_CS_DT model

From Figure 16, it has been observed that the 20LF_CS_DT model has predicted compressive strength of GGBS mixed concrete with $\pm 2.79 \%$ confidence and $\pm 6.76 \%$ prediction intervals.

\subsubsection{Artificial Neural Networks}

The Artificial Neural Network models have been constructed using Levenberg-Marquardt (LM), Gradient Descent with Moment (GDM), Gradient Descent with Adaptive (GDA), BFGS Quasi-Newton (BFG), Scaled Conjugate Gradient (SCG), and Gradient Descent (GD) algorithms to predict the compressive strength of GGBS mixed concrete. The LM, BFG, SCG, GDM, GD, and GDA ANN models are designated as LM_CS_ANN, BFG_CS_ANN, SCG_CS_ANN, GDM_CS_ANN, GD_CS_ANN, and GDA_CS_ANN, respectively. The training and testing performance of the ANN models of compressive strength of GGBS mixed concrete is shown in Table 11.

Table 11 - Performance of ANN models for CS of GGBS Mixed Concrete

\begin{tabular}{|c|c|c|c|c|c|c|}
\hline \multirow{2}{*}{$\begin{array}{l}\text { DT Model } \\
\text { Architecture }\end{array}$} & \multicolumn{3}{|c|}{ Training Performance } & \multicolumn{3}{|c|}{ Testing Performance } \\
\hline & $\begin{array}{c}\text { RMS } \\
\text { E }\end{array}$ & $\mathbf{R}$ & MAE & $\begin{array}{c}\text { RMS } \\
\text { E }\end{array}$ & $\mathbf{R}$ & MAE \\
\hline & & 0001 & $\begin{array}{c}.177 \\
5\end{array}$ & 3.63 & 0 & $\begin{array}{c}3.081 \\
9\end{array}$ \\
\hline $\mathrm{BFC}$ & 7701 & 10 & $\begin{array}{c}0.064 \\
3\end{array}$ & 3.47 & $\begin{array}{c}0.907 \\
3\end{array}$ & $\begin{array}{c}2.316 \\
6\end{array}$ \\
\hline SCC & 663 & 0.983 & $\begin{array}{c}0.077 \\
5\end{array}$ & 4.7391 & $\begin{array}{c}0.745 \\
8\end{array}$ & $\begin{array}{c}3.393 \\
3\end{array}$ \\
\hline $\begin{array}{l}\text { GDM } \\
\mathrm{N}\end{array}$ & 0814 & $\begin{array}{c}0.978 \\
0\end{array}$ & $\begin{array}{c}0.020 \\
0\end{array}$ & 3.4055 & $\begin{array}{c}0.909 \\
0\end{array}$ & $\begin{array}{c}2.792 \\
3\end{array}$ \\
\hline GD & 554 & $\begin{array}{c}0.911 \\
9\end{array}$ & $\begin{array}{c}0.110 \\
8\end{array}$ & .5053 & $\begin{array}{c}0.412 \\
2\end{array}$ & $\begin{array}{c}4.342 \\
6\end{array}$ \\
\hline $\begin{array}{l}\text { GDA } \\
\mathrm{N}\end{array}$ & 0.1101 & $\begin{array}{c}0.947 \\
5\end{array}$ & $\begin{array}{c}0.163 \\
1\end{array}$ & 7.6175 & $\begin{array}{c}0.498 \\
5\end{array}$ & $\begin{array}{c}5.107 \\
0\end{array}$ \\
\hline
\end{tabular}

From Table 11, it has been observed that the GDM_CS_ANN model has achieved a maximum performance of 0.9566 in predicting the compressive strength of GGBS mixed concrete. The performance curve of the GDM_CS_ANN model is shown in Figure 17.

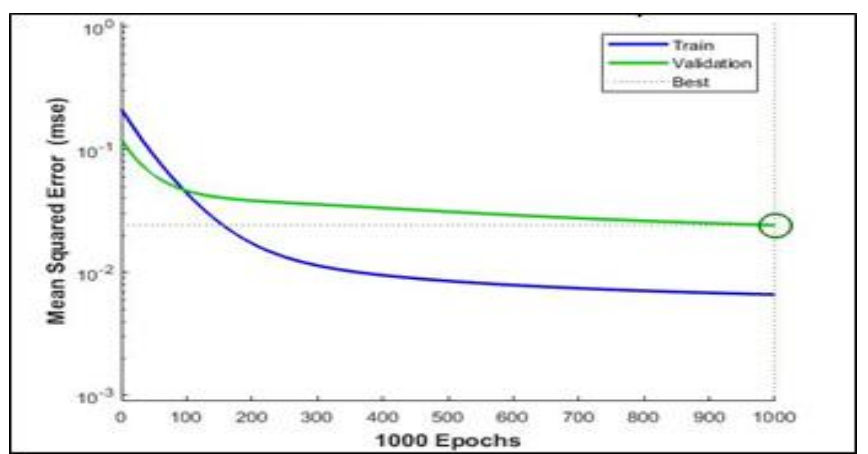

Figure 17. Performance of GDM_CS_ANN model for predicting CS of concrete

Figure 17 shows that the best prediction of compressive strength of GGBS mixed concrete has been achieved at the $1000^{\text {th }}$ iteration with RMSE $=3.4055$, which is comparatively less than other ANN models. The GDM_CS_ANN model has been used to predict the compressive strength and predicted compressive strength has been compared with laboratory compressive strength, as shown in Figure 18.

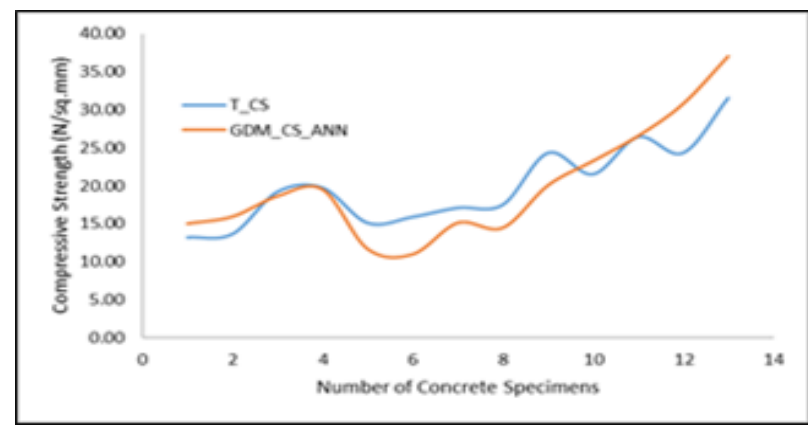

Figure 18. Comparison of test and predicted CS using GDM_CS_ANN model

Figure 18 shows that the GDM_CS_ANN model has predicted the compressive strength of GGBS mixed concrete, which is equal to laboratory results. Hence, the GDM_CS_ANN model may be used for predicting the preliminary compressive strength of GGBS mixed concrete. The actual vs predicted plot is mapped to calculate the coefficient of determination. The coefficient of determination $\left(\mathrm{R}^{2}\right)$ has been calculated for the predicted compressive strength of GGBS mixed concrete using GDM_CS_ANN, as shown in Figure 19.

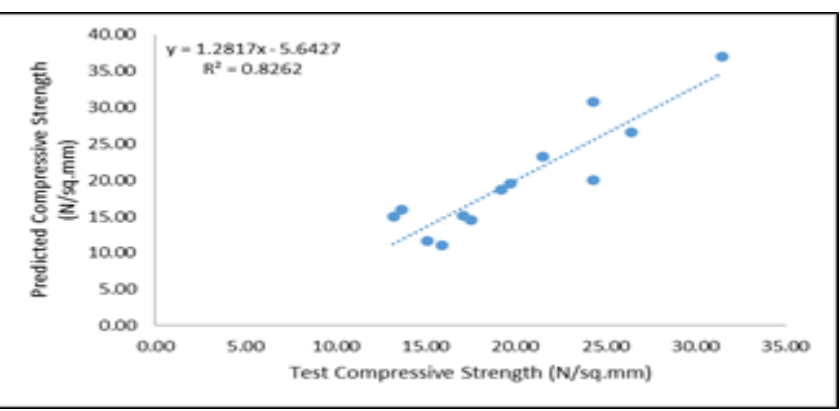

Figure 19. R2 for the predicted CS using GDM_CS_ANN model

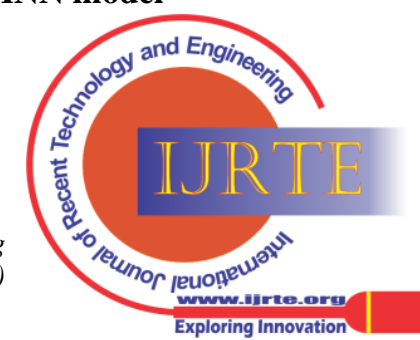


From Figure 19, it has been observed that the GDM_CS_ANN model has predicted the compressive strength of GGBS mixed concrete with $\mathrm{R}^{2}=0.8262$. The residuals in predicting the compressive strength of GGBS mixed concrete have been calculated, as shown in Figure 20.

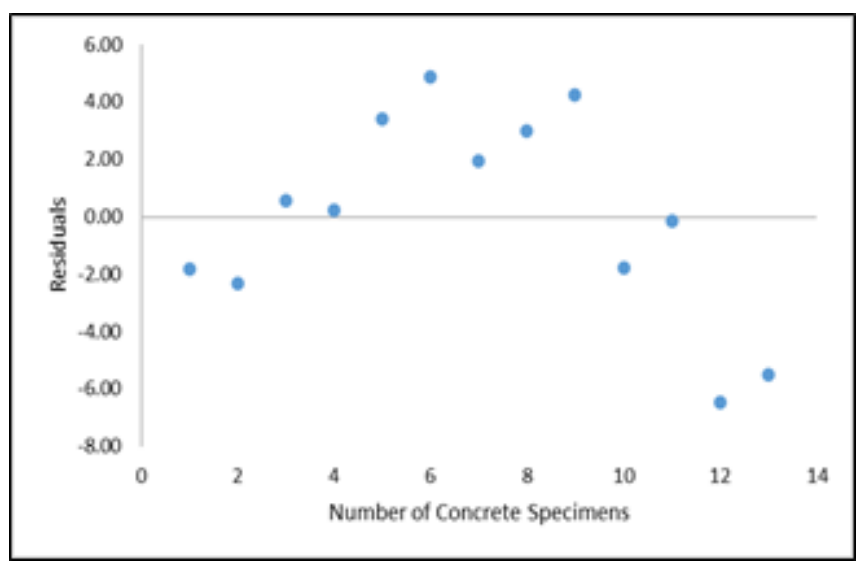

Figure 20. Residuals plot for predicted CS using GDM_CS_ANN model

From Figure 20, it has been observed that the GDM_CS_ANN model has predicted the compressive strength of GGBS mixed concrete with the variation of \pm 8.0 in compressive strength. The confidence and prediction interval of computed compressive strength of GGBS mixed concrete using the GDM_CS_ANN model has been mapped, as shown in Figure 21.

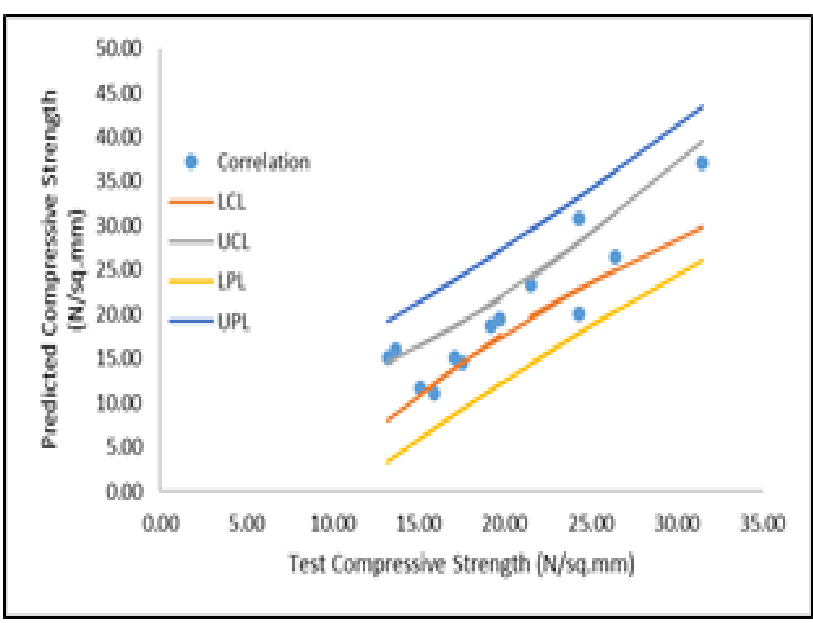

Figure 21. Confidence and prediction interval of computed CS using GDM_CS_ANN model

From Figure 21, it has been observed that the GDM_CS_ANN model has predicted compressive strength of GGBS mixed concrete with $\pm 6.53 \%$ confidence and $\pm 15.84 \%$ prediction intervals.

\subsubsection{Optimum Performance Model}

The CS_MLR, LinK_CS_SVM, 20LF_CS_DT, and GDM_CS_ANN models have been identified as the best architectural AI models. The performance of the best architectural AI models has been compared to identify the optimum performance AI model for predicting the compressive strength of GGBS mixed concrete, as shown in Figure 22.

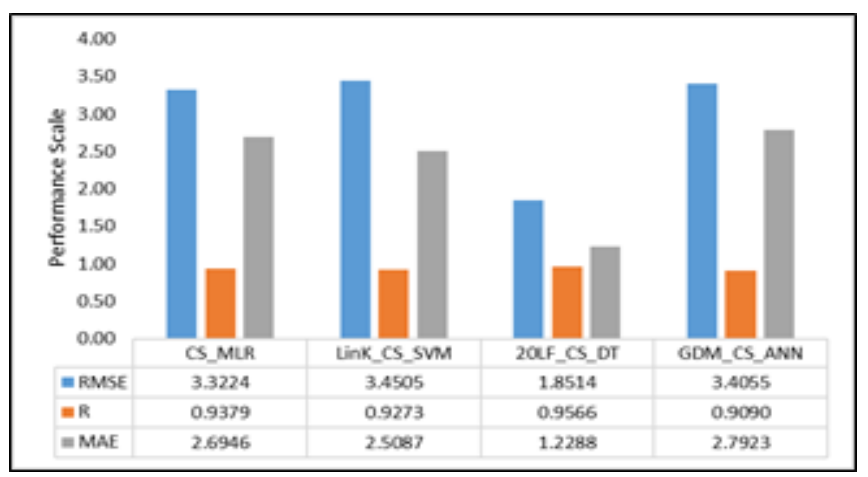

Figure 22. Performance comparison of the best architectural AI models for predicting CS

From Figure 22, it has been observed that the 20LF_CS_DT model of the decision tree AI approach has predicted compressive strength of GGBS mixed concrete with MAE = $1.2288, \mathrm{RMSE}=1.8514$, and $\mathrm{R}=0.9566$, respectively. The coefficient of determination (R2) of 20LF_CS_DT shows a strong correlation with laboratory test results of compressive strength of GGBS mixed concrete[23]. The 20LF_CS_DT model outperformed the CS_MLR, LinK_CS_SVM, and GDM_CS_ANN in predicting the compressive strength of GGBS mixed concrete. Hence, the 20LF_CS_DT model has been identified as the optimum performance model and can be used to predict the compressive strength of GGBS mixed concrete.

\section{V.COMPARISON WITH PUBLISHED MODELS}

The 20LF_CS_DT model has been identified as the optimum performance model with a performance of 0.9566 . The performance of the 20LF_CS_DT model has been compared with published models, as shown in Figure 23.

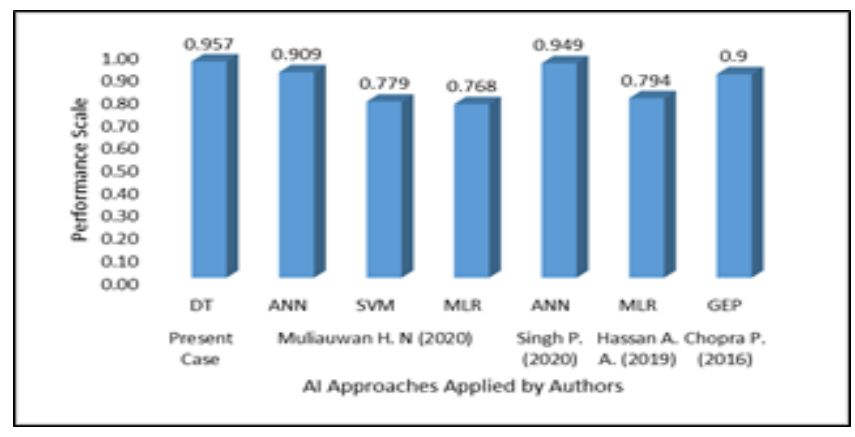

Figure 23. Comparison of performance of DT model with published models in the literature

Figure 23 shows that the 20LF_CS_DT model outperformed the published models in predicting the compressive strength of concrete. Hence, the 20LF_CS_DT model can be used to predict the compressive strength of waste materials or bymaterial mixed concrete.

\section{VI.CONCLUSIONS}

The literature study shows that the AI approaches can predict the compressive strength of concrete. In the present study, the regression analysis, support vector machine, decision tree, and artificial neural network.

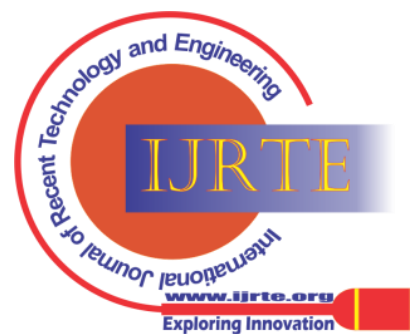




\section{Computation of Compressive Strength of GGBS Mixed Concrete using Machine Learning}

AI approaches were used to predict GGBS mixed concrete's compressive strength. The following conclusions are mapped from the present study -

- The Pearson's correlation coefficient shows that the compressive strength of GGBS mixed concrete is influenced by days of curing.

- The performance of developed models shows that machine learning outperformed the statistical methods and deep learning with a performance of 0.9566 .

- The statistical methods outperformed deep learning with a performance of 0.9379 .

- The comparison of performance 20LF_CS_DT models outperformed the published models in the literature study.

From the study, it has been concluded that the decision tree with 20 leaf-size performs better and predicts the compressive strength of GGBS mixed concrete with high accuracy.

\section{REFERENCES}

1. Akkurt Sedat, Ozdemir Serhan, Tayfur Gokmen, Akyol Burak (2003), The use of GA-ANNs in the modelling of compressive strength of cement mortar, Cement and Concrete Researh, 33, pp. 973-979, doi:10.1016/S0008-8846(03)00006-1.

2. Baykasoglu Adil, Dereli Turkay, Tanis Serkan (2004), Prediction of cement strength using soft computing techniques, Cement and Concrete Research, 34, pp. 2083-2090, doi:10.1016/j.cemconres.2004.03.028.

3. Bilim Cahit, Atis Cengiz D., Tanyildizi Harun, Karahan Okan (2009), Predicting the compressive strength of ground granulated blast furnace slag concrete using artificial neural network, Advances in Engineering Software, 40, pp. 334-340, doi:10.1016/j.advengsoft.2008.05.005.

4. Cementitious Materials, Sustainable Concrete - The Leading Material in Sustainable Construction, https://www.sustainableconcrete.org.uk/Sustainable-Concrete/Whatis-Concrete/Cementitious-Materials.aspx

5. Chopra Palika, Sharma Rajendra Kumar, Kumar Maneek (2014), Predicting compressive strength of concrete for varying workability using regression models, International Journal of Engineering \& Applied Science, 6(4), pp. 10-22.

6. Chopra Palika, Sharma Rajendra Kumar, Kumar Maneek (2016), Prediction of compressive strength of concrete using artificial neural network and genetic programming, Advances in Materials Science and Engineering, Article ID 7648467, pp. 1-10, http://dx.doi.org/10.1155/2016/7648467.

7. Cortes, Corinna; Vapnik, Vladimir N. (1995), "Support-vector networks, Machine Learning, 20(3), pp. 273-297.

8. Dantas Adriana Trocoli Abdon, Leite Monica Batista, Nagahama Koji de Jesus (2013), Prediction of compressive strength of oncrete containing construction and demolition waste using artificial neural networks, Construction and Building Materials, 38, pp. 717-722, http://dx.doi.org/10.1016/j.conbuildmat.2012.09.026.

9. Dias W. P. S., Pooliyadda S. P. (2001), Neural networks for predicting properties of concrete with admixtures", Construction and Building Materials, 15, pp. 371-379, PII: S0950-0618Ž01.00006-X.

10. Guang Ni Hong, Zong Wang Ji (2000), Prediction of compressive strength of concrete by neural networks, Cement and Concrete Research, 30, pp. 1245-1250, PII: S0008-8846(00)00345-8.

11. Hair Jr. J, Wolfnibarger M. C.,Ortinau, D. J. \& Bush, R. P. (2013), Essentials of Marketing, New York,Mc Graw Hill

12. Hasan Monjurul M., Kabir Ahsanul (2011), Prediction of compressive strength of concrete from early age test results, 4th Annual Paper Meet and 1st Civil Engineering Congres, 22-24 Dec. 2011, Dhaka, Bangladesh, ISBN: 978-984-33-4363-5.

13. Hassan A. A., Mawat Mohammed J., Dawood A. S. (2019), Predictiong of compressive strength of concrete containing pozzolanic materials by applying neural networks, International Journal of Civil Engineering and Technology, 10(2), pp. 526-537, Article ID: IJCIET_10_02_053, http://iaeme.com/Home/issue/IJCIET?Volume=10\&Issue=2.
14. Kabir Ahsanul, Hasan Monjurul, Miah Md. Khasro (2013), Strength prediction model for concrete, International Journal on Civil and Environmental Engineering, 2(1), pp. 14-19, doi: 01.IJCEE.2.1.

15. Karni J. (1974), Prediction of compressive strength of concrete, Matériaux et Construction, 7, pp. 197-200.

16. Lai Sergio, Mauro Serra (1997), Concrete strength prediction by means of neural network, Consturction and Building Materials, 11(2), pp. 93-98.

17. Lee Seung Chang (2003), Prediction of concrete strength using artificial neural networks, Engineering Structures, 25, pp. 849-857, doi:10.1016/S0141-0296(03)00004-X.

18. Muliauwan H. N., Prayogo D., Gaby G., Harsono K. (2020), Prediction of concrete compressive strength using artificial intelligence methods, 2nd International Conference on Sustainable Infrastructure, Journal of Physics: Conference Series, 1625, pp. 1-10, doi:10.1088/1742-6596/1625/1/012018.

19. Neville A. M. (2011), Properties of concrete, 5th Edition, Pearson education limited, England.

20. Rao Rama Mohan, Rao H. Sudarsana (2012), Prediction of compressive strength of concrete with different aggregate binder ratio using ANN model, International Journal of Engineering Researh and Technology, 1(10), pp. 1-10.

21. Silva Priscia F. S, Moita Gray Farias, Arruda Vanderci Fernandes (2020), Machine learing techniques to predict the compressive strength of concrete, Revista Internacional de Metodos Numericos Para Calculo y Diseno En Ingenieria, 36(4), pp. 1-14, doi: 10.23967/j.rimni.2020.09.008.

22. Singh Priyanka, Khaskil Partha (2020), Predictiong of compressive strength of green concrete with admixutes using neural networks, IEEE International Conference on Computing, Power and Communication Technolgoies, Galgotias University, Greater Noida, UP, India, 2-4 Oct. 2020, ISBN: 978-1-7281-5070-3.

23. Smith G. N. (1986), Probability and statistics in civil engineering An introduction, Collins, London.

24. Wu Nan-Jing (2021), Predicting the compressive strength of concrete using an RBF-ANN model, Applied Sciences, 11, pp. 1-10, https://doi.org/10.3390/app11146382.

25. Yeh I. C. (1998), Modeling of strength of high-performance concrete using artificial neural networks, Cement and Concrete Research, 28(12), pp. 1797-1808.

\section{AUTHORS PROFILE}

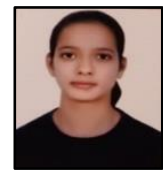

Ms Swati is pursuing MTech at the Department of Civi Engineering, Rajasthan Technical University, Kota, Rajasthan. She completed her BTech from Swami Keshvanand Institute of Technology (SKIT), Jaipur, Rajasthan. Ms Swati is applying the Machine Learning, and Deep Learning Artificial Intelligence Approaches in Concrete Technology to predict the properties of concrete.

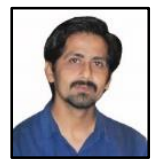

Mr. Jitendra Khatti is pursuing $\mathrm{PhD}$ at the Department of Civil Engineering, Rajasthan Technical University, Kota, Rajasthan. He completed his Master's from Rajasthan Technical University, Kota. He published many research articles in International and National Journals/ Conferences. The research areas of Mr. Jitendra Khatti are Applications of Artificial Intelligence in Civil Engineering, Stabilization of Soil, Pavement Engineering, Use of Waste in Concrete and Tall Structures.

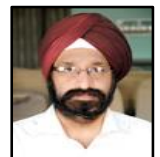

Dr. Kamaldeep Singh Grover is a Professor at the Department of Civil Engineering, Rajasthan Technica University, Kota, Rajasthan. Dr. Kamaldeep Singh Grover is specialized in Geotechnical Engineering and Structura Engineering. The research areas of Dr. Kamaldeep Singh Grover are Artificial Intelligence, Concrete Technology, Tall Structures, Pavement Engineering and Stabilization of Soil.

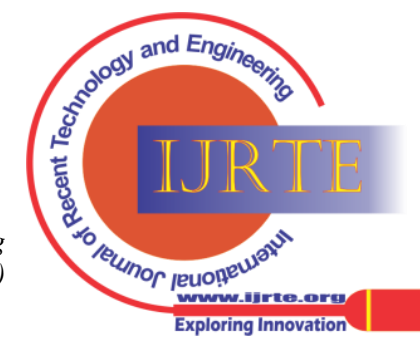

